\title{
An automated method for measuring time-course of gas production of feedstuffs incubated with buffered rumen fluid
}

\author{
J.M.W. BEUVINK, S.F. SPOELSTRA* \& R.J. HOGENDORP \\ DLO-Research Institute for Livestock Feeding and Nutrition, P.O. Box 160, NL 8200 AD \\ Lelystad, Netherlands.
}

Received 1 April 1992; accepted 18 June 1992

\begin{abstract}
A system for automated registration of gas production in time upon incubation of feedstuffs with rumen fluid is presented. The system is based on weighing the amount of fluid replaced by fermentation gas, followed by calculation to gas volume and registration by a data logger. Incubations with glucose, rice starch and crystalline cellulose showed glucose to be fermentated at the fastest rate and cellulose at the slowest. The major source of variation was rumen fluid from different days. An example of a gas production curve is given for the incubation of grass and its cell wall fraction (obtained after treatment with Neutral Detergent reagent).
\end{abstract}

Keywords: digestibility, in vitro gas production, fermentation rate, automated method

\section{Introduction}

In vitro incubation with rumen fluid (Tilley \& Terry, 1963) or cellulolytic enzymes (McQueen \& van Soest, 1975) is widely used to estimate digestibility of ruminant feedstuffs. Yet these methods do not measure digestibility, but the solid residue after incubation. This gives erroneous results when soluble non-digestible products are formed (Tetlow et al., 1987) and when small particles are lost in the supernatant. To overcome these problems, Menke et al. (1979) proposed to measure gas produced when feedstuffs are incubated with buffered rumen fluid.

In addition to digestibility, the rate of degradation of feedstuffs is of crucial importance to maintain optimum rumen function and is an important feed parameter governing intake (Demeyer, 1981). Rumen degradation rates are now mainly estimated by incubating feed samples in porous nylon bags (Mehrez \& Ørskov, 1977) which is a laborious method, and again only the fraction that is solubilised is measured. Alternatively, time related measurements of fermentation end products like $\mathrm{pH}$ (Malestein \& Van 't Klooster, 1986), heat (Arieli \& Werner, 1989) and gas (Van der

* Corresponding author 
Meer et al., 1990; Krishnamoorty et al., 1991; Merry et al., 1991) have been proposed.

Gas production is directly related to rumen fermentation, relatively easy to measure and therefore appears to be a suitable parameter for rumen fermentation rate studies. The methods described so far (Van der Meer et al., 1988; Merry et al., 1991) require frequent periodical readings for over $48 \mathrm{~h}$, making them less fit as routine laboratory methods. We describe here a system for automated registration of gas production in time. This automated system allows 24 samples to be measured at the same time.

\section{Materials and methods}

\section{Description of the apparatus}

A schematic diagram of the apparatus is shown in Fig. 1. Gas production was measured by a liquid displacement system connected to a collection vessel placed on a balance. The collection vessel was placed $20 \mathrm{~cm}$ above the displacement bottle to achieve an equilibrium between the pressure in the displacement bottle and the sum of atmospheric and hydrostatic pressures. To minimize changes in hydrostatic pressure, an overflow tube was placed in the collection vessel. Gas production caused liquid to stream towards the collection vessel until a new equilibrium was established.

The system comprised 24 units (fermentation flask plus displacement system)

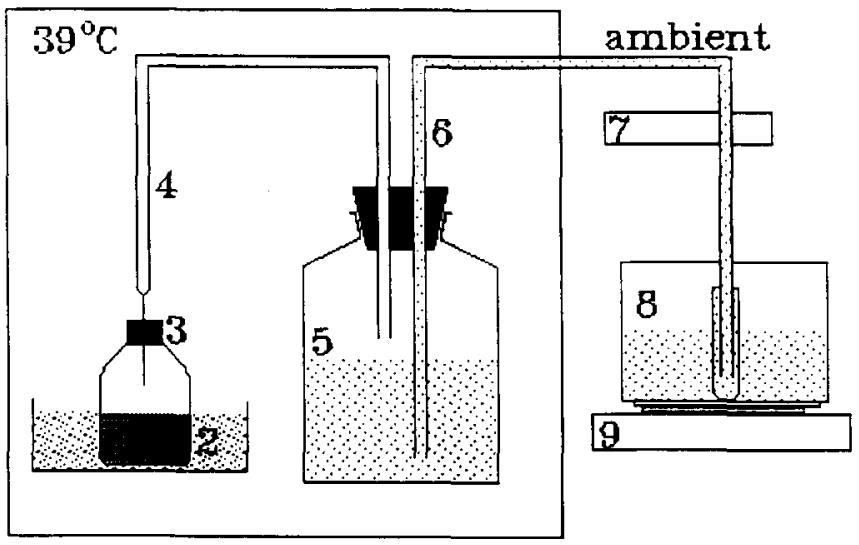

Fig. 1. Schematic diagram of the apparatus. $1=$ Fermentation bottle $(100 \mathrm{ml}$ serum flask $) .2$ = Shaking waterbath $\left(50 \mathrm{rev} . / \mathrm{min} ; 39^{\circ} \mathrm{C}\right)$. 3 = Syringe needle piercing butyl rubber cap (Suba Seal Manuf.). 4 $=$ Butyl rubber tubing. $5=$ Water displacement bottle $(1-1)$ with 700 $\mathrm{ml}$ saturated $\mathrm{NaCl}$ solution at $\mathrm{pH} 1.6=$ Tygon tubing. $7=24$-way valve. $8=$ Collection vessel with overflow tube to minimize changes in hydrostatic pressure. $9=$ Balance with analogue output to data logger. 


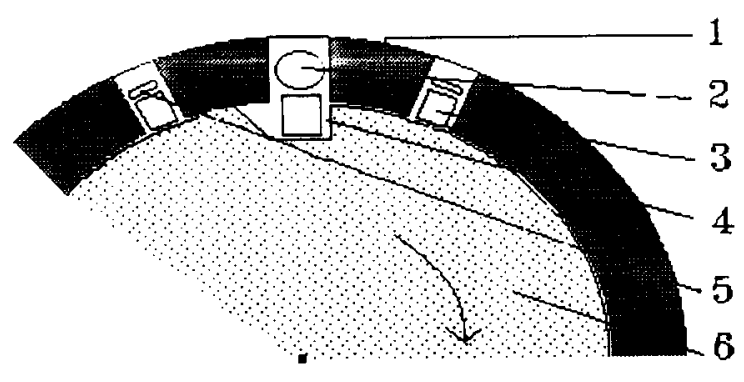

Fig. 2. Detail of 24-way valve. $1=$ Fixed outer circle. $2=$ Open tube. 3 $=$ Metal cilinder. $4=$ Notch, permitting one tube to be opened at a time. $5=$ Closed tube. $6=$ Rotating inner part, arrow indicates direction of movement.

using only one balance. All 24 tubes (Tygon, inner diameter $2.3 \mathrm{~mm}$ ) were led through a 24-way valve (see Fig. 2) before entering their own overflow tube in the vessel on the balance. This 24-way valve permitted only one of the tubes to be open. The amount of liquid displaced by the fermentation gas was collected and weighed. On a signal from a camshaft turning synchronously with the rotation disc, this weight was calculated to volume ( $\mathrm{ml}$ gas) and stored in the memory of a data logger for later calculations. Subsequently, the next tube was opened and the events repeated. The rotation time of the disc was set at $25 \mathrm{~min}$, so every sample was measured once at this time interval.

A gas-tight seal of all the tubes and connections was ensured by closing the butyl rubber tubes with a clamp and letting the apparatus run. In case of leakage, liquid would stream back to the displacement bottle. If the system was gas-tight, heating up of the air in the displacement bottles caused liquid to flow to the collection vessel until an equilibrium was reached (usually after a few hours). At this moment the apparatus was ready to use. Measurements were started by piercing the syringe needle through the butyl rubber cap of the fermentation bottle and opening the clamp.

\section{Experimental}

Rumen fluid was obtained from two rumen fistulated wether sheep, kept on a daily diet of $800 \mathrm{~g}$ hay and $200 \mathrm{~g}$ concentrates and fed at 8.00 and 16.00 hours. From the two sheep equal amounts of rumen fluid were taken $2 \mathrm{~h}$ after morning feeding and collected in a thermostated flask filled with $\mathrm{CO}_{2}$. The rumen fluid was filtered through two layers of cheese cloth and mixed (1:2) with the anaerobic medium described by Menke et al. (1979).

Substrate (400 mg $\pm 10 \mathrm{mg}$ ) was weighed into the fermentation bottles, which were then carefully flushed with oxygen free $\mathrm{CO}_{2}$ for 2 minutes and closed with a butyl rubber cap (Suba Seal Manuf.). By inserting a syringe needle through the bottle closure, $60 \mathrm{ml}$ of buffered rumen fluid was added to the substrate under continuous flushing with oxygen free $\mathrm{CO}_{2}$. An extra needle was placed to maintain atmospheric pressure. After removing the needles, the bottle was placed in the waterbath and connected to the water displacement system. The 24-way valve and the clamp on the butyl rubber tube were opened to let the system re-equilibrate for approx. $1 \mathrm{~min}$. 
After this had been done for all 24 units, measurements were started. Time zero was defined as the moment at which the buffered rumen fluid was added to the substrate.

The following well-defined, homogenous substrates were incubated in quadruplicate on four diffent days: glucose (J.T. Baker, Deventer, Netherlands), rice starch and crystalline cellulose (both from Sigma, St. Louis, MO, USA). Time course of gas production was followed during $48 \mathrm{~h}$. In parallel incubations, gas production from four blanks (buffered rumen fluid without substrate) was measured. For every sample, the gas volumes stored in the memory of the data logger were calculated to cumulative gas productions and corrected for gas production from the blank. Gas production was expressed in millilitres gas per gram organic matter (OM). Gas production after $24 \mathrm{~h}$ from four experiments was used to estimate variation of gas production within and between rumen liquor from different days.

To illustrate the possibilities of the automated system, grass and the cell wall fraction from this gras were incubated as described above. Grass was oven dried ( 70 ${ }^{\circ} \mathrm{C}$ ) and milled over a $1 \mathrm{~mm}$ sieve. Cell wall fraction was prepared by boiling $100 \mathrm{~g}$ grass for $1 \mathrm{~h}$ with 1 litre Neutral Detergent reagent (Goering \& van Soest, 1970), subsequent filtration over nylon gaze (mesh $40 \mu \mathrm{m}$ ) and washing three times with hot water. The residue was dried under vacuum $\left(40^{\circ} \mathrm{C}\right)$ and used for gas production measurements.

\section{Results}

Cumulative gas production curves for the three substrates are given in Fig. 3 (results of one day). Each curve represents the average of four replicates. Glucose was fermented instantaneously without a lag phase, whereas rice starch was fermented

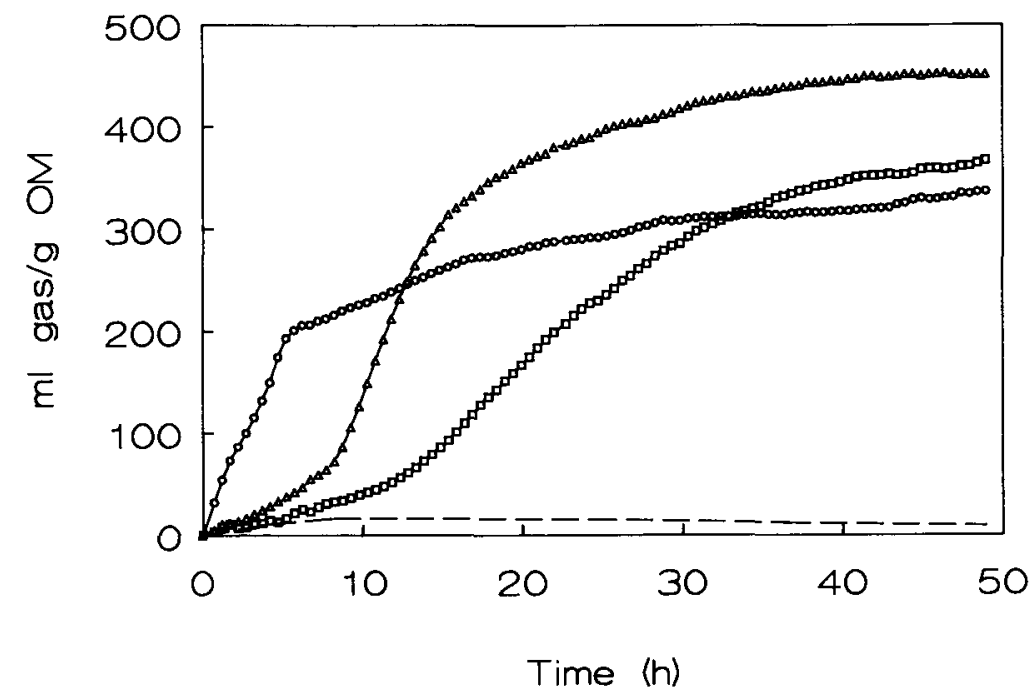

Figure 3. Cumulative gas production patterns for glucose $(O)$, rich starch $(\triangle)$ and cellulose $(\square)$ and average SD throughout the curves $(---)$. Each point is the average of 3 replicates. 
Table 1. Results of analysis of variance of gas production after $24 \mathrm{~h}$ incubation, for three substrates and rumen fluid from four days.

\begin{tabular}{lccc}
\hline & Glucose & $\begin{array}{l}\text { Rice } \\
\text { starch }\end{array}$ & Cellulose \\
DF between days & 3 & 3 & 3 \\
DF within days & 11 & 12 & 9 \\
Grand mean (ml gas g & & & \\
SED $^{\text {a }}$ & 305 & 403 & 257 \\
Between days mean square & 10.3 & 15.1 & 10.2 \\
Within days mean square $^{\mathrm{b}}$ & $1374^{*}$ & 1546 & $5072^{*}$ \\
\hline
\end{tabular}

${ }^{a}=$ Standard Error of Difference of means. ${ }^{b}=$ Estimated variance of gas production. ${ }^{*}=$ Significant at $\alpha=0.01$

slower and crystalline cellulose the slowest. Highest total gas production was observed upon incubation of rice starch.

Table 1 shows the results from analysis of variance of total gas production after $24 \mathrm{~h}$ upon incubation of glucose, rice starch or cellulose, on four different days of incubation. For glucose and cellulose the between-series mean square was much greater than the within-series mean square. This could be ascribed to significantly different gas productions $(\mathrm{P}<0.01)$ for rumen fluid from different days. For rice starch there was a trend $(\mathrm{P}=0.055)$ for gas production to differ with rumen fluid from different days. Differences in total gas production between these carbohydrates

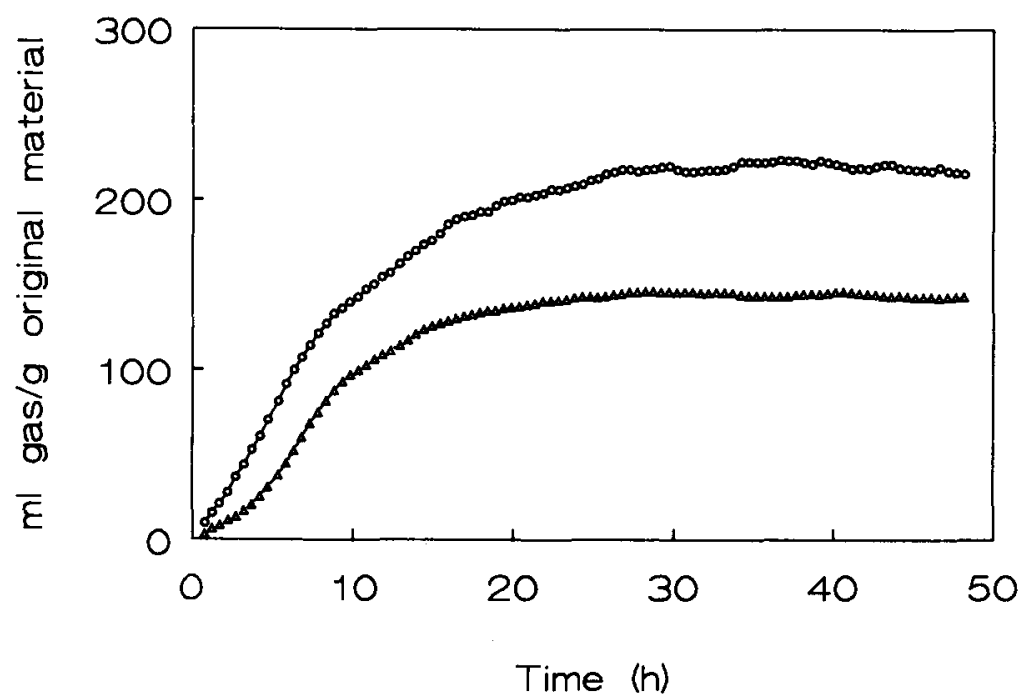

Fig. 4. Gas production from $1 \mathrm{~g}$ grass $(O)$ and the cell wall fraction (Neutral Detergent Residue) originating from $1 \mathrm{~g}$ grass $(\triangle)$. Each point is the average of 3 replicates. 
can be explained by differences in fermentation pattern (Beuvink et al., 1992). Sometimes little or no gas production was observed, eventhough there was no evidence for leakage. Such observations were excluded from further calculations. In the experiment described in Table 1, this was the case for 3 out of 48 incubations.

Figure 4 shows results from incubation of grass and cell wall fraction. From $1 \mathrm{~g}$ grass, $0.48 \mathrm{~g}$ of cell wall was obtained. The treatment for cell wall preparation resulted in a loss of components from which gas could be produced (probably soluble sugars and polysaccharides like fructosans, and to a lesser extent protein).

\section{Discussion}

The use of the automated system described here, may be a valuable instrument in determining rumen fermentation kinetics in vitro. By releasing the pressure every 25 minutes, little build up of pressure occurs in the fermentation bottles.

Giger-Reverdin (1990) suggested corrections for changes in atmospheric and hydrostatic pressure when measuring water displacement by gas in the RUSITEC. Such corrections were not needed in our system. Changes in gas volumes caused by atmospheric and hydrostatic pressure were calculated to be less than $0.5 \%$. Changes in temperature however, must be avoided, because of their immediate effect on gas volumes.

The major source of variation in gas production for incubations with glucose and cellulose was caused by batches of rumen fluid taken at different days. This agrees with observations made by other authors (Mehrez \& Ørskov, 1977; Krishnamoorty et al., 1991). For rice starch there was only a trend to differ in gas production with rumen fluid from different days. Variation between rumen fluid from different sheep was avoided by mixing equal amounts of rumen fluid from two sheep. It was found preferable to incubate samples at least triplicate because sometimes, for unknown reasons, a very different fermentation pattern was observed for one of the replicates.

The non-automated method of measuring gas production in time has been used in evaluation of genetic varieties of fodder plants (van der Meer et al., 1988), estimation of starch and protein availability in processed sorghum grain (Xiong et al., 1990) and determining the rate of fermentation of energy supplements (Krishnamoorty et al., 1991). The automated method presented in this paper allows easier measurement of rumen fermentation kinetics in vitro. We intend to use this system for evaluating enzyme addition to grass silage.

\section{Acknowledgements}

We thank Ad van Beers for skilled assistance in designing and manufacturing the apparatus and Bert Wieman for writing the software for data manipulation. This work was financially supported by the Programmacommissie Landbouw en Biotechnologie (PcLB) in Wageningen. 


\section{References}

Arieli, A. \& D. Werner, 1989. A comparison between fermentation heat of forages and organic matter digestibility determined by in vitro incubation with rumen fluid. Animal Feed Science and Technology 23: 333-341.

Beuvink, J.M.W. \& S.F. Spoelstra, 1992. Interactions between substrate, fermentation end-products, buffering systems and gas production upon fermentation of different carbohydrates by mixed rumen microorganisms in vitro. Applied Microbiology and Biotechnology 37: 505-509.

Demeyer, D.I., 1981. Rumen microbes and digestion of plant cell walls. Agriculture and Environment 6: 295-337.

Giger-Reverdin, S., 1990. Estimation simple et fiable des dégagements gazeux issus de fermentation. Annales Zootechnique 39: 173-178.

Malestein, A. \& TH. van 't Klooster, 1986. Influence of ingredient composition of concentrates on rumen fermentation rate in vitro and in vivo and on roughage intake of dairy cows. Journal of Animal Physiology and Animal Nutrition 55: 1-13.

McQueen, R. \& P.J. van Soest, 1975. Fungal cellulase and hemicellulase prediction of forage digestibility. Journal of Dairy Science 58: 1482-1491.

Krishnamoorty, U., H. Soller, H. Steingass \& K.H. Menke, 1991. A comparative study on rumen fermentation of energy supplements in vitro. Journal of Animal Physiology and Animal Nutrition 65: $28-35$.

Menke, K.H., L. Raab, A. Salewski, H. Steingass, D. Fritz, \& W. Schneider, 1979. The estimation of digestibility and metabolizable energy content of ruminant feedstuffs from the gas production when they are incubated with rumen liquor in vitro. Journal of Agricultural Science, (Cambridge) 193: 217-222.

Mehrez, A.Z. \& E.R. Ørskov, 1977. A study of artificial fibre bag technique for determining the digestibility of feeds in the rumen. Journal of Agricultural Science (Cambridge) 88: 645-660.

Merry, R.J., M.K. Theodorou, M.G. Raurich \& M.S. Dhanoa, 1991. Use of head space pressure in rumen batch cultures to assist in determination of the nutritive value of silage. In: Proceedings 'Forage Conservation towards 2000', Landbauforschung Völkenrode, Sonderheft 123, pp. 451-454.

Tetlow, R.M., V.C. Mason \& G. Deschard, 1987. Treatment of whole crop cereals with alkali. 2. Voluntary intake and digestibility by sheep of rye, barley and wheat crops ensiled with sodium hydroxide. Animal Feed Science and Technology 18: 271-281.

Tilley, J.M.A. \& R.A. Terry, 1963. A two stage technique for the in vitro digestion of forage crops. Journal of the British Grassland Society 18: 104-111.

Van der Meer, J.M., G. Wever \& S. Bediye 1988. Rumen bacteria for evaluation of enzymatically changed animal feeds and genetic varieties of fodder plants. Analytica Chimica Acta 213: $177-185$.

Xiong, Y., S.J. Bartle, R.L. Preston \& Q. Meng, 1990. Estimating starch availability and protein degradation of steam-flaked and reconstituted sorghum grain through a gas production technique. Journal of Animal Science 68: 3380-3385. 